\title{
Scanning Tunneling Microscopy and Photoemission Studies of Self-organised Ag Nanostructures on the N-Modified Cu(001) Surface
}

\author{
Paola Finetti ${ }^{1,3}$, Luisa Ferrari ${ }^{2}$, Sergio D'Addato ${ }^{3,4}$ \\ ${ }^{1}$ Elettra-Sincrotrone Trieste S.C.p.A. , 34149 Trieste, Italy \\ ${ }^{2}$ CNR-ISM, Via Fosso del Cavaliere 100, 00133 Roma, Italy \\ ${ }^{3}$ Dipartimento FIM, Università di Modena e Reggio Emilia, via G. Campi 213/a, 41125 Modena, \\ Italy \\ ${ }^{4}$ CNR, Istituto Nanoscienze, via G. Campi 213/a, 41125 Modena, Italy
}

There has been a strong interest in methods of creating nanometer scale structures and in particular forming one- and two-dimensional electron confinement structures. Self-organisation has been recognised as a promising way for growing large nanostructure domains with sufficiently regular size and spacing as required for the observation of quantum well states. We investigated the electronic properties of $\mathrm{Ag}$ nano-structures on $\mathrm{N}$-modified $\mathrm{Cu}(001)$. This system is an example of epitaxial growth confined on nanoscale regions due to the occurrence of an adsorbate induced reconstruction. Using a combination of Scanning Tunneling Microscopy and Angle Resolved Photoemission Spectroscopy techniques we were able to determine the morphology and the growth mode of $\mathrm{Ag}$ on $\mathrm{N}$-modified $\mathrm{Cu}(001)$ surface and the occurrence of quantum size effects in the electron properties of $\mathrm{Ag}$ nanostripes and nanoislands, evidenced in the occurrence of quantum well states.

Keywords: self-assembling, Ag, N, Cu(001) surface, quantum well states, STM, ARPES 


\section{Introduction}

The bottom-up approach in the design and realization of nanostructure assemblies is a wellestablished method in nanoscience, and still it presents some fascinating aspects: in particular, fabrication of 2-D self-organized patterns and their use for creating regular assemblies of dots, wires and stripes is one of the most interesting phenomena in physics and chemistry, also for technological application [1-12]. In particular, adsorption of atomic nitrogen on the $\mathrm{Cu}(001)$ surface is a very good example of self-organisation [13-14]: at $\mathrm{N}$-coverage $\Theta_{\mathrm{N}}$ below saturation (saturation occurs at $\Theta_{\mathrm{N}}=0.5 \mathrm{ML}$ ) the adsorption results in fact in the formation of regular arrays of square $\mathrm{N}$ islands with $\mathrm{c}(2 \times 2)$ internal periodicity that run parallel to the $<100>$ azimuth. The size of the square islands does not depend on the $\mathrm{N}$-coverage and is equal to about $5 \times 5 \mathrm{~nm}^{2}$. The spacing between islands along the array is given by one line of $\mathrm{Cu}$ atoms, while the spacing between the arrays is inversely proportional to the $\mathrm{N}$ coverage. This peculiar arrangement of the adsorbates leaves stripe-shaped domains of clean $\mathrm{Cu}$ having a regular width. It was found that this periodic arrangement is caused by difference of surface stress in the clean and nitrided domains, and their competition with the domain boundary energy $[15,16]$. The regular island morphology can be monitored with Scanning Tunneling Microscopy (STM) [13, 14], with Low Energy Electron Diffraction (LEED) [17,18] and Surface X-ray Diffraction (SXRD), in the last two cases by directly observing four-fold satellite peaks which appears around the (10) diffraction spots [16, 19]. When the $\mathrm{N}$ coverage reaches a value $\Theta_{\mathrm{N}}=0.5 \mathrm{ML}$, the square islands coalesce, with formation of an almost continuous $\mathrm{N}$ layer, with some interruptions caused by trenches parallel to $<110>$ directions, which have a width of few nanometers and a height of a single atomic layer $[13,14]$. More recently, ribbon-like nanopatterns were obtained in vicinal regions toward $<100>$ directions, with formation of $\mathrm{N}$ islands of rectangular shapes [20]. The $\mathrm{N}$-modified $\mathrm{Cu}$ surface exhibits also strong reactivity to atomic $\mathrm{H}$ exposure, with formation of $\mathrm{NH}$ species at the surface and, by increasing the amount of $\mathrm{H}$ dosage, with formation and desorption of ammonia [21]. 
STM experiments found out that when transition metals such as $\mathrm{Cu}, \mathrm{Fe}, \mathrm{Ni}, \mathrm{Ag}, \mathrm{Co}, \mathrm{Au}$ are deposited on the $\mathrm{N}$-modified $\mathrm{Cu}(001)$ surface, epitaxial growth at its initial stages occurs preferentially on the clean $\mathrm{Cu}$ stripes [1,22-27], rather than on the $\mathrm{N}$-covered parts of the surface. Therefore metal particles and stripes can be grown on the clean $\mathrm{Cu}$ areas, but the evolution of the growth with the metal coverage depends strongly on the particular metal used. For instance, the origin of preferential growth of $\mathrm{Fe}$ islands on bare $\mathrm{Cu}(001)$ areas was assigned to inclusion of $\mathrm{Fe}$ atoms at very low Fe coverage stage. These inclusions worked as centers of nucleation for the growth of $2 \mathrm{D}$ Fe islands on top of the $\mathrm{Cu}$ bare surface areas. After the bare $\mathrm{Cu}$ areas are completely covered, the Fe nanostructured films extend over the N-covered patches. X-ray Absorption Fine Structures (XAFS) studies confirmed the preferential growth of $\mathrm{Fe}$ islands on the bare $\mathrm{Cu}$ surfaces for $\Theta_{\mathrm{N}}<0.5 \mathrm{ML}$, with Fe arranged in fcc lattice [28-30], and with the presence of some disorder in the islands, with inhomogeneous lattice distortion caused by tetragonal expansion and the presence of surface atoms arranged in nano-martensitic phase. When Fe is adsorbed on saturated $\mathrm{c}(2 \times 2)-\mathrm{N}$ surface, XAFS data analysis are compatible with a geometry where the Fe atoms substitute the $\mathrm{Cu}$ atoms underneath the $\mathrm{N}$ layer. $\mathrm{Fe}-\mathrm{Cu}$ bond length values are instead typical of $\mathrm{Fe}$ in a fcc site [30]. SXRD experiments on the same system were also performed; Crystal Truncation Rods (CTR) analysis substantially confirmed the results of XAFS [19]. Co and Fe nanostructured films on Nmodified $\mathrm{Cu}(001)$ exhibited also interesting magnetic properties, as revealed by magneto-optical Kerr effect [31], dichroism in photoemission [32] and absorption [33].

Ag nanostructured films on $\mathrm{N}$-modified $\mathrm{Cu}$ surfaces were investigated, for low Ag coverage, with STM, showing the possibility of creating single crystal Ag nanowires on sub-saturated c(2x2)$\mathrm{N} / \mathrm{Cu}(001)$. The $\mathrm{Ag}$ nanowires formed on the bare $\mathrm{Cu}$ areas between the arrays of $\mathrm{N}$ islands and are therefore aligned along the $<100>$ direction, up to 4 atomic layers thick $[1,34]$. The growth of $\mathrm{Ag}$ on the bare $\mathrm{Cu}$ areas followed the same evolution as the formation of $\mathrm{Ag}$ ultrathin films on clean $\mathrm{Cu}(001)$, with formation for low coverage of a $\mathrm{c}(10 \times 2)$ superstructure, followed by a simple pseudoexagonal overlayer structure [35]. 
On the other hand, the effect of reduced dimensionality on the electron properties of $\mathrm{Ag}$ ultrathin films shown itself in a spectacular way by the onset of quantum well states, observed with Angle Resolved Photoemission Spectroscopy (ARPES) and due essentially to the confinement of Ag electrons by the film-vacuum and film-substrate interface. The films were grown on a variety of single crystal surfaces, either metals or semiconductors [36-44]. Aim of this work is to investigate the effect of the $\mathrm{N}$-induced nanopatterning of $\mathrm{Cu}(001)$ on the $\mathrm{Ag}$ electronic states, in particular, the effect of lateral confinement induced by $\mathrm{N}$ surface nanostructuring on the QW. The present study follows the morphology of the growth of $\mathrm{Ag}$ on the $\mathrm{N}$ modified $\mathrm{Cu}(001)$ surface by means of STM from the very early stages and up to $8 \mathrm{ML}$. The electronic structure of the Ag overlayer is studied by means of angular integrated photoemission spectroscopy (PES) and ARPES.

\section{Experimental}

The $\mathrm{Cu}(001)$ surface was cleaned by cycles of Ar sputtering at $1 \mathrm{keV}$ ion impact energy and annealing at $550^{\circ} \mathrm{C}$. The cleanliness of the surface thus obtained was checked by LEED and PES and by STM where applicable. The $\mathrm{N}$ overlayer was prepared by sputtering the $\mathrm{Cu}(001)$ surface with $\mathrm{N}_{2}$ at medium ion impact energy $(500 \mathrm{eV})$ until the accumulated charge on the sample (i.e. the product of the sample drain current and the sputtering time) was of the order of $90 \mu \mathrm{C}$. Cross-check also with previous STM observations shown that with this dosage the N precoverage is about 0.25 ML. The $\mathrm{N}_{2}$ sputtering was followed by prolonged annealing (at least one hour) of the sample at $350^{\circ} \mathrm{C}$. This procedure resulted in a sharp LEED and large domains of $\mathrm{N}$ islands arrays as revealed also by STM. The photoemission experiments were carried on VUV-Photoemission beamline and on APE, beamlines both at the synchrotron radiation laboratory of Elettra, Trieste, during two different runs. STM data were acquired in a chamber connected with the APE endstation.

The $\mathrm{N}-\mathrm{Cu}(001)$ surface prior to Ag deposition was characterized by means of low energy electron diffraction (LEED) every time. This technique allows to detect the formation of long arrays of 
$\mathrm{c}(2 \mathrm{x} 2)-\mathrm{N}$ islands due to the presence of extra diffraction spots to be attributed to long periodic structures such as the islands arrays. [13, 14, 22]. Ag was evaporated at room temperature from an Ag bead heated in an alumina crucible and no annealing procedure was applied to the overlayer. The amount of deposited Ag was determined by means of a calibrated quartz microbalance. Two $\mathrm{Cu}(001)$ crystals were employed for the ARPES and STM experiments and identical Ag evaporators were mounted at the same distance from the sample in all the experimental chambers.. to ensure the same amount of deposited Ag observed in STM and (AR)PES experiments. ARPES data were acquired with $k_{\|}$varying along the $<100>$ and $<110>$ azimuthal direction.

\section{Results and discussion}

\section{A. STM results}

Figure 1 a-b shows some examples of STM images from the N pre-covered surface. Our images are similar to the ones obtained in previous studies in which the $\mathrm{N}$ growth mode has been described accurately $[13,14,22]$ and here we report some results for the sake of clarity. The $\mathrm{N}$ islands appear as depressions in the image. From Fig. 1a) it can be estimated that the N coverage is about 0.25 ML, i.e. about $50 \%$ of the initial surface is made of two domains of $c(2 \times 2)-\mathrm{N}$ islands arrays and by domains of clean unreconstructed $\mathrm{Cu}(001)$ stripes running along the $<100>$ azimuthal direction.. Fig. 1b shows faceting of the island at the island corners and the occasional coalescence of $\mathrm{N}$ islands at the junction between domains of $\mathrm{N}$ islands with edges terminating along the $<110>$ azimuthal direction. This peculiarity in the $\mathrm{N}$ overlayer is rarely found and it is reported here as an example. 


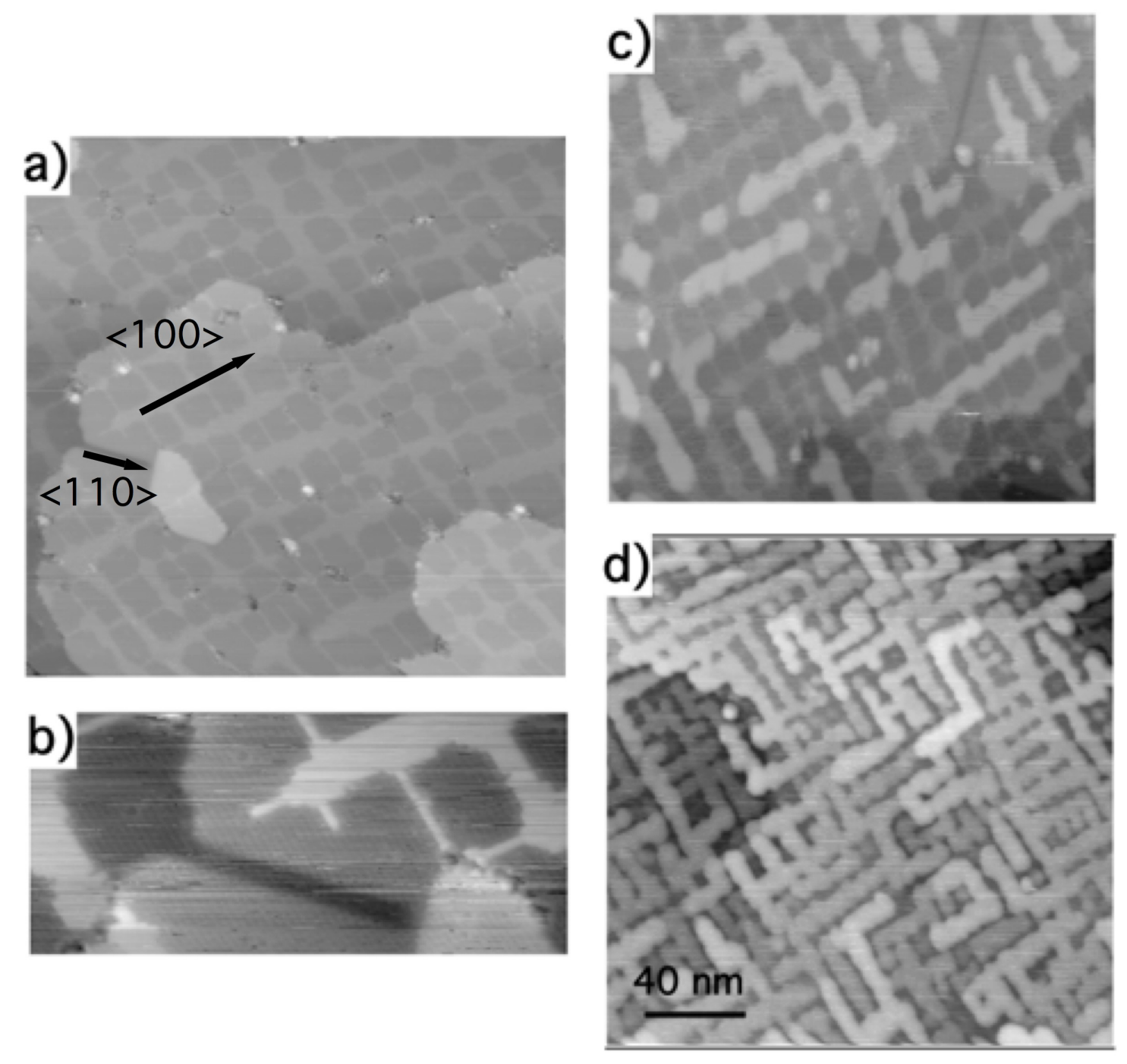

Figure 1. a) and b) $0.25 \mathrm{ML}$ of $\mathrm{c}(2 \times 2)-\mathrm{N} / \mathrm{Cu}(001)$. The $\mathrm{N}$ covered parts appear as depressions. The $\mathrm{N}$ islands are about $\left.5 \times 5 \mathrm{~nm}^{2} . \mathrm{c}\right) 0.25 \mathrm{ML}$ of $\mathrm{c}(2 \times 2)-\mathrm{N} / \mathrm{Cu}(001)$ plus $0.1 \mathrm{ML}$ of $\mathrm{Ag}$ (showing as striped protrusions). d) 0.25 $\mathrm{ML}$ of $\mathrm{c}(2 \times 2)-\mathrm{N} / \mathrm{Cu}(001)$ and $0.5 \mathrm{ML}$ of $\mathrm{Ag}$. Small, but high and round protrusions appearing occasionally on 1 a),c) and d) which are due to the tip. 
Fig. 1c)-d) and Fig. 2 a)-e) report the growth of $\mathrm{Ag}$ on the $\mathrm{N}$ modified $\mathrm{Cu}$ surface, from the very early stage ( $0.1 \mathrm{ML}$ of $\mathrm{Ag})$ up to coverage values corresponding to a volume of 8 flat $\mathrm{Ag}$ monolayers on $\mathrm{Cu}(001)$. The growth of $\mathrm{Ag}$ on bare $\mathrm{Cu}(001)$ has been extensively studied with a number of techniques. In summary, at a thickness of up to $1 \mathrm{ML}$, the $\mathrm{Cu}$ and $\mathrm{Ag}$ lattice mismatch determines a growth of $\mathrm{Ag}$ in the shape of a quasi hexagonal $\mathrm{c}(2 \mathrm{x} 10)$ structure $[34,35,45,46]$. Note that room temperature $\mathrm{Cu}(001)-\mathrm{Ag}$ alloying, confined to the $2 \mathrm{D}$ surface, was predicted for very low Ag coverages $\left(\Theta_{\mathrm{Ag}}<0.13 \mathrm{ML}\right)[47]$. From the data shown in Fig. 2c) we cannot give evidence of this process. At higher thickness the Ag overlayer grows as unreconstructed $\operatorname{Ag}(111)[34,46]$. Also the early growth (up to $2 \mathrm{ML}$ ) of $\mathrm{Ag}$ on $\mathrm{N}$ modified $\mathrm{Cu}(001)$ was reported in the past by STM $[1,33]$. It was shown [34] that the growth of Ag in this case proceeds in the same guise as on the clean $\mathrm{Cu}(001)$ surface, i.e., with a $\mathrm{c}(2 \times 10)$ periodicity for the first layer of $\mathrm{Ag}$ growing on clean $\mathrm{Cu}$ and forming an unreconstructed $\mathrm{Ag}(111)$ layer for $\mathrm{Ag}$ stripes of higher thickness. In this paper we consider much higher coverage values than previously reported and the whole sequence of $\mathrm{Ag}$ overlayers is here discussed. Two types of Ag growth modes can be identified: for $0<\Theta_{\mathrm{Ag}}<2 \mathrm{ML}$ the growth is entirely confined on the $\mathrm{Cu}$ stripes (see Fig. 1c),d) and Fig. 2 a)) and proceeds predominantly in a layer by layer fashion. In particular, at the Ag coverage of $0.5 \mathrm{ML}$ all the $\mathrm{Cu}$ stripes are covered by $\mathrm{Ag}$ with a thickness of 1 atomic layer (the $\operatorname{Ag}(111)$ step size is $2.36 \AA$ ) and occasionally double layered $\mathrm{Ag}$ islands can be observed (see Fig. 1d). This finding is consistent with some marginal error in the determination of the $\mathrm{N}$ pre-coverage and with a small error in the calibration of the deposited Ag. The LEED observations confirm the $\mathrm{c}(2 \times 10)$ periodicity of the Ag overlayer at this Ag coverage. 


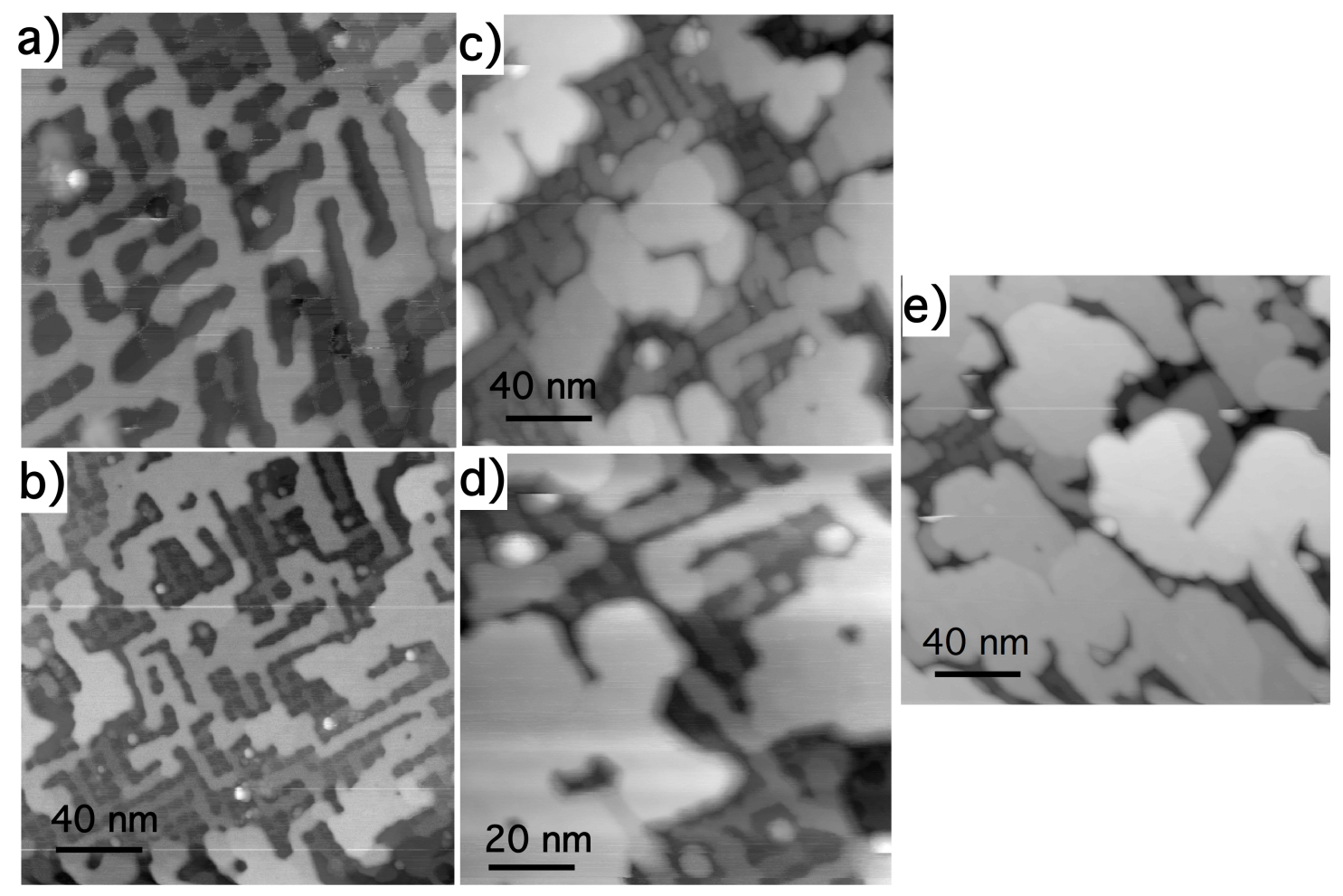

Figure 2. In all the figures the $\mathrm{Cu}(001)$ surface was modified by the adsorption of $0.25 \mathrm{ML}$ of c(2x2)-N. a) $1 \mathrm{ML}$ of Ag. b) $2 \mathrm{ML}$ of $\mathrm{Ag}$. c) and d) $4 \mathrm{ML}$ of Ag. e) $8 \mathrm{ML}$ of $\mathrm{Ag}$. In all images, sharp round shaped protrusions are tip effects.

At about 1ML of deposited Ag thickness, the Ag forms predominantly a double layer (see Fig. 2a), but the height of the striped Ag domains can reach up to 6 (see Fig. 3a) atomic layers and the LEED shows the presence of $\operatorname{Ag}(111)$ domains. At about $2 \mathrm{ML}$ we observed the onset of islands formation (see Fig 2b). The growth of these 2D islands is both lateral and vertical, and the LEED shows a pattern consistent with an $\mathrm{Ag}(111)$ films. Above $2 \mathrm{ML}$ the lateral growth becomes predominant, with heights reaching 7 atomic layers at about $4 \mathrm{ML}$ of deposited Ag volume (see Fig. 3b), although non-negligible areas of $\mathrm{N}$-covered $\mathrm{Cu}$ could still be observed with STM even for the highest Ag nominal thickness (8 ML). In this case the islands can reach a height of 10 monolayers (see Fig. 3c). The Ag islands display an atomically flat top and peculiar faceting induced by the N-modified substrate. It can also be noticed that their thickness tends to be rather uniform across the surface. 
This can be seen both from the STM images and from the line profiles, shown on fig. 3c. Note that the profiles were acquired in regions where the Ag coverage is more variable. Also, in the profile at $8 \mathrm{ML}$ there is no safe assignment of the baseline to an $\mathrm{Ag}$ free area. The $10 \mathrm{ML}$ height of the highest island is then an estimate.
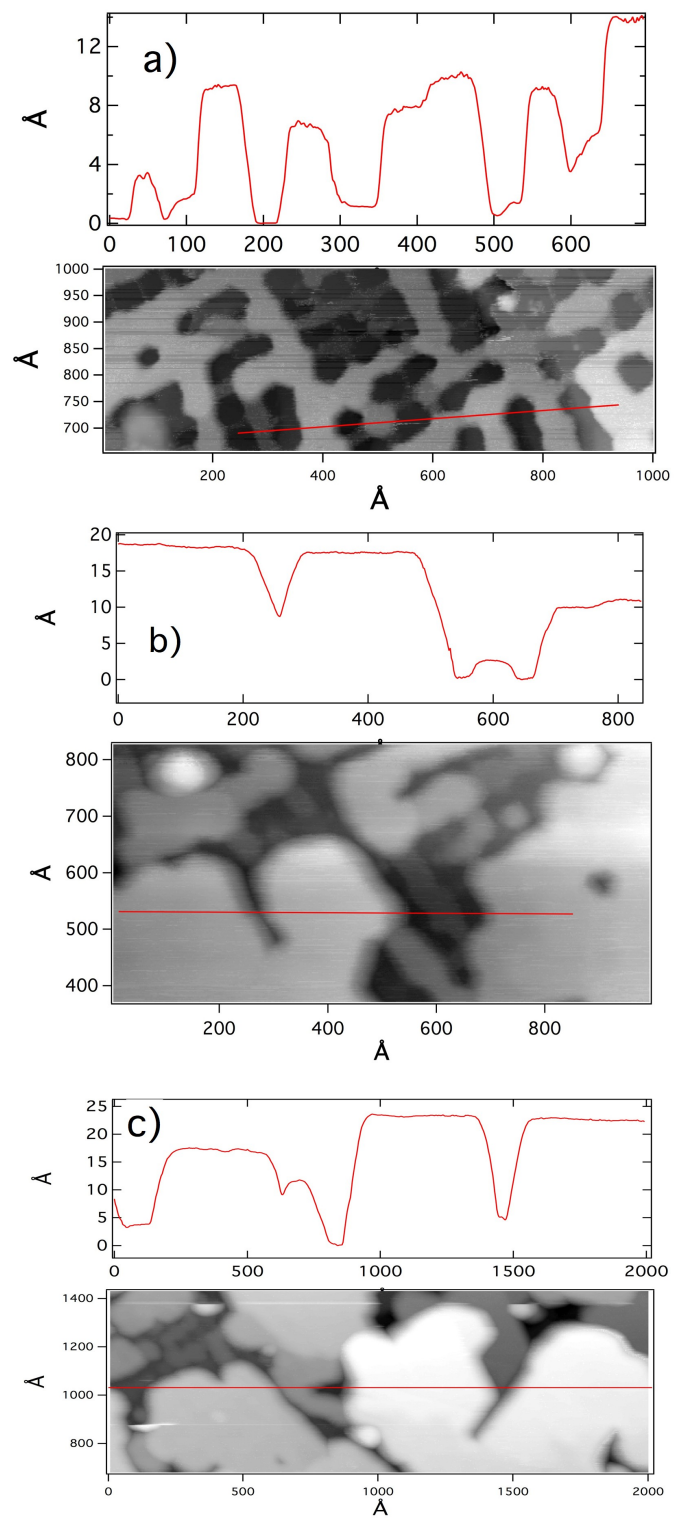

Figure 3. Line profiles from STM images. a) 1 ML. b) 4ML. c) 8 ML.

In summary, we observed a layer by layer type of growth throughout the $\mathrm{Ag}$ coverage range reported in this study, despite the non uniform substrate conformation. From our STM data we 
could not find clear evidence of displacement of $\mathrm{N}$ atoms upon Ag growth. However, $\mathrm{N}$ segregation was observed previously on Co nanostructured films grown on the same surface, as a result of strain induced by the formation of Co nano-islands [48]. It is quite possible that the flatness of Ag islands observed especially for high Ag coverage may be induced by the surfactant effect of segregated $\mathrm{N}$ atoms, which we could not observe directly by STM images. The flat top of the islands at high coverage and the presence of a LEED pattern typical of $\operatorname{Ag}(111)$ surface would suggest uniformity also of the substrate, and this finding would be consistent with displacements of $\mathrm{N}$ atoms when $\mathrm{Ag}$ starts covering the $\mathrm{N}$ patches, or their segregation. Finally we remind that the Ag overlayer was not annealed and the film morphology is the result of the room temperature mobility of the Ag atoms. As a result of the high mobility, the $\mathrm{Ag}$ stripes and islands show an atomically flat top at all coverage studied.

\section{B. Photoemission results}

The (AR)PES experiments were carried out by varying the Ag coverage in the range between 0.5 ML and $20 \mathrm{ML}$. As observed by STM, in this range the morphology of the Ag overlayer evolves from the predominant presence of stripes $\left(0.5 \mathrm{ML} \leq \Theta_{\mathrm{Ag}}<2 \mathrm{ML}\right)$ to a 2-D island structure ( $\left.\Theta_{\mathrm{Ag}}>4 \mathrm{ML}\right)$. 


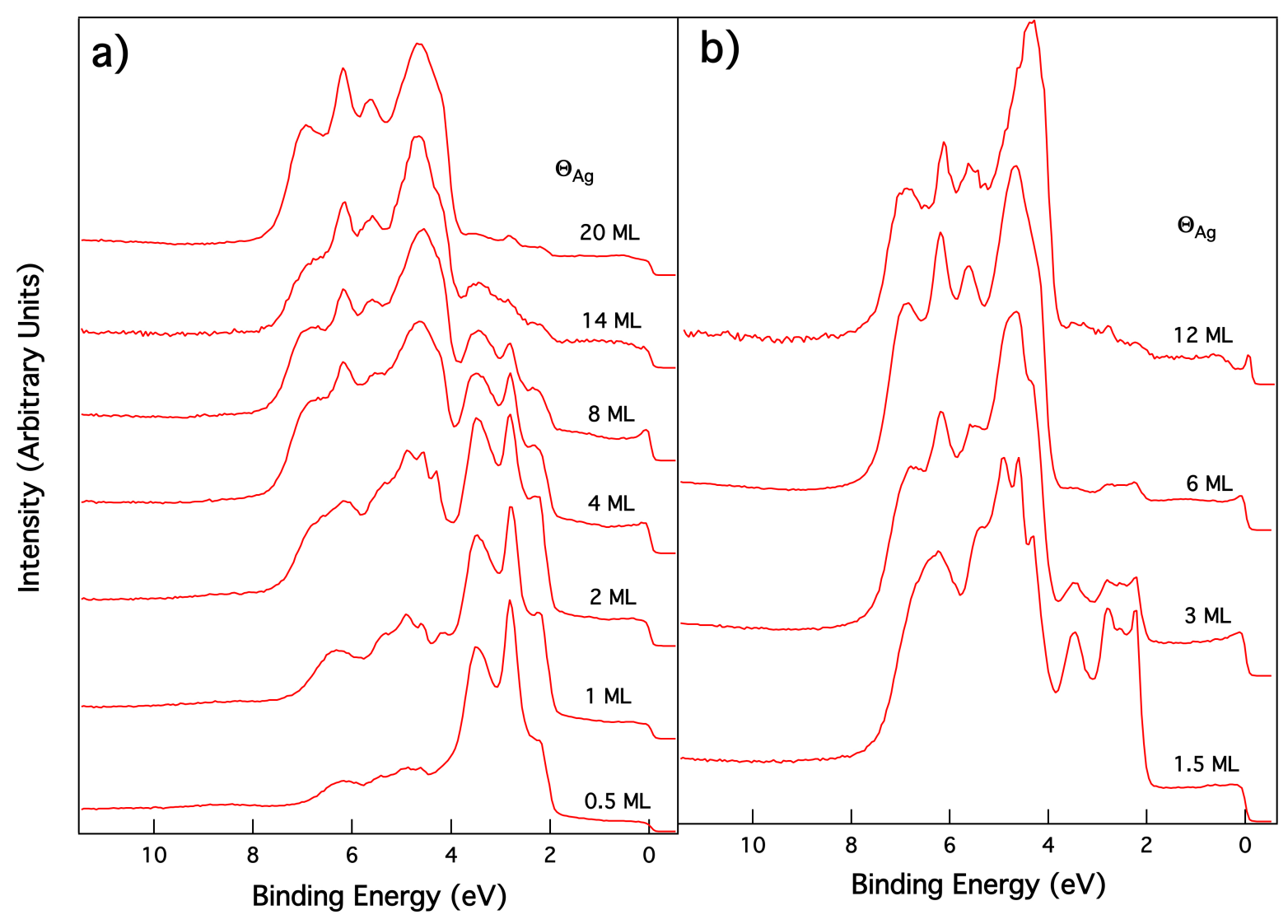

Figure 4. Normal emission spectra integrated over an angle of $14^{\circ}$ acquired at a photon energy $h v=47.7 \mathrm{eV}$ for a variable Ag coverage $\Theta_{A g}$ a) Ag evaporated onto a $0.25 \mathrm{ML} \mathrm{c}(2 \times 2)-\mathrm{N} / \mathrm{Cu}(001)$ surface. b) Ag evaporated on a clean $\mathrm{Cu}(001)$ surface).

Normal emission photoemission spectra (Fig. 4) show that $\mathrm{Cu} 3 \mathrm{~d}$ bands (around $2 \mathrm{eV}-4 \mathrm{eV}$ binding energy) are more persistent in $\mathrm{Ag}$ films grown $\mathrm{c}(2 \mathrm{x} 2)-\mathrm{N} / \mathrm{Cu}(001)$ than in $\mathrm{Ag}$ films grown on clean $\mathrm{Cu}(001)$ at the same $\mathrm{Ag}$ grown quantity. This effect can be readily explained from STM data. In the former case in fact, there are regions of the surface covered by $\mathrm{N}$-islands arrays, and $\mathrm{Ag}$ tends to be confined only on the clean $\mathrm{Cu}$ areas, so that a part of the surface tend to be "passivated" by the adsorbed $\mathrm{N}$ atoms, remaining uncovered. The spectrum taken at $20 \mathrm{ML}$ on the $\mathrm{N}$ precovered surface is very similar to the one taken at $12 \mathrm{ML}$ on clean $\mathrm{Cu}$. This shows that at $20 \mathrm{ML}$ thickness the $\mathrm{Ag}$ film covers the entire $\mathrm{Cu}$ surface and the growth proceeds as it would do on clean $\mathrm{Cu}$. Note that the angular integration of the normal emission spectra shown in Fig. 4 is $14^{\circ}$. This explains the low 
visibility of QW states and of the Ag surface Schockley state, which is instead clearly visible in the angle resolved data (see below).

The photoemission data presented in this paper are also the first experimental evidence of the quantum size effect [4] in $\mathrm{Ag}$ nano-structured films formed onto the $\mathrm{N}$-modified $\mathrm{Cu}(001)$ surface. QW of $\mathrm{Ag}$ films on $\mathrm{Cu}$ were observed for $\mathrm{Ag}$ grown on $\mathrm{Cu}(111)$ [39].

Fig.4 reports ARPES data taken from 4 ML Ag grown on sub-saturated N-precovered $\mathrm{Cu}(001)$. The sub-saturation $\mathrm{N}$ pre-coverage was chosen to be $0.25 \mathrm{ML}$, corresponding to the $\mathrm{N}$ coverage giving rise to the STM images shown in Fig.1a)-b), while the STM image corresponding to $4 \mathrm{ML} \mathrm{Ag}$ grown on $\mathrm{N}(0.25 \mathrm{ML})-\mathrm{Cu}$ is shown in Fig. 2d).
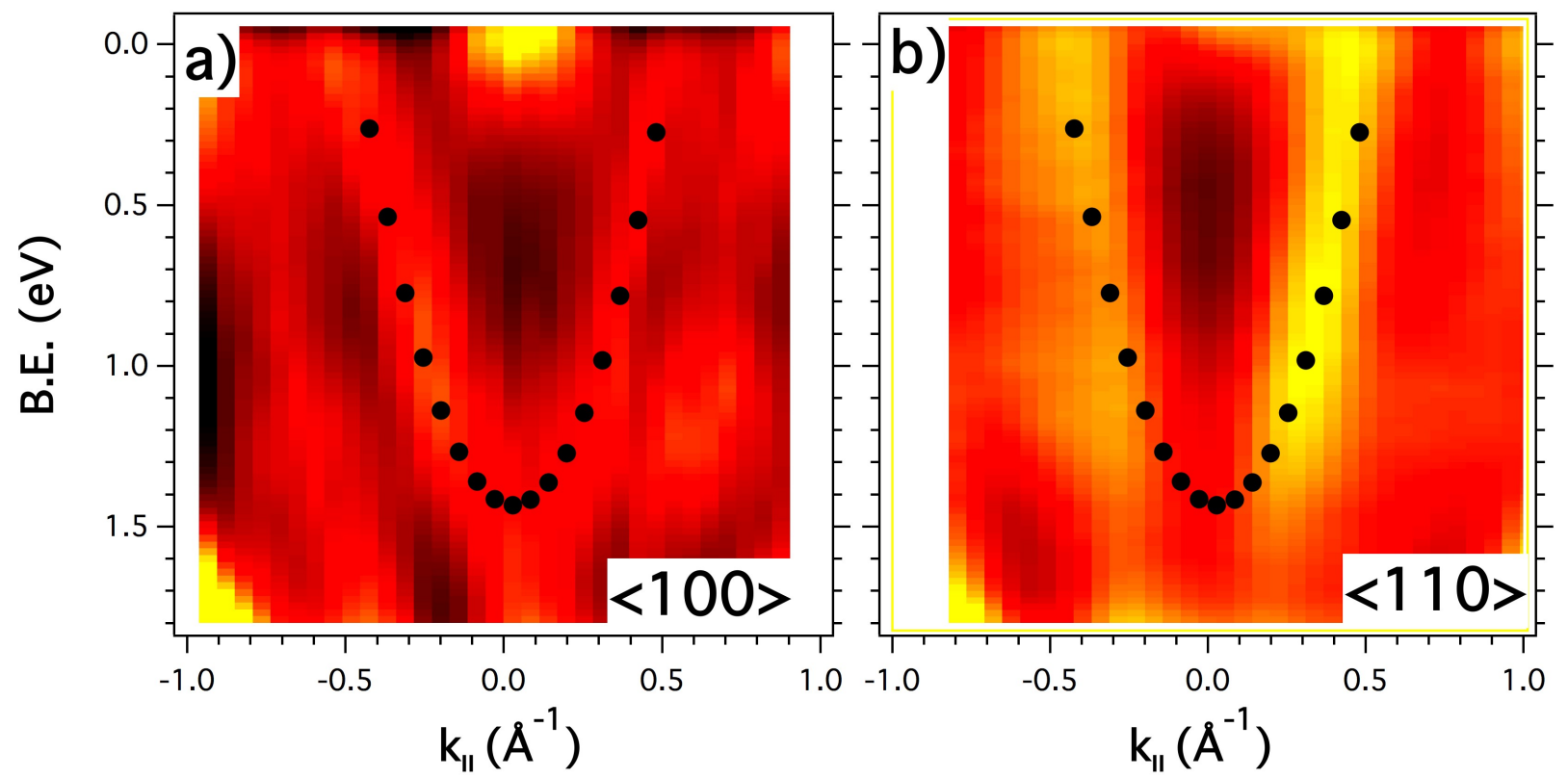

Figure 5. ARPES data acquired on $4 \mathrm{ML}$ of $\mathrm{Ag}$ deposited on $0.25 \mathrm{ML} \mathrm{c}(2 \times 2)-\mathrm{N} / \mathrm{Cu}(001)$. Black dotted line: measured dispersion of the QW states. a) ARPES along the $<100>$ azimuth. b) ARPES along the $<110>$ azimuth. Photon energy $\mathrm{hn}=47.7 \mathrm{eV}$. Note that the colour scale of Fig.5a and $5 \mathrm{~b}$ was compressed to increase the visibility of QW.

The photoemission data clearly shows the electron confinement effects in the form of QW states with parabolic dispersion in $\mathrm{k}_{\|}$. The coverage at which the QW states begins to be observed is 4 ML. The QW states are generally broad, which is an indication of non perfectly uniform thickness 
contributing to the confinement effect. They are more intense along the $<100>$ azimuth, where also a second QW can be observed. This second QW is too broad for a safe assignment of its $\mathrm{BE}$ and its dispersion is not shown. The higher order QW can be observed also along the $<110>$ azimuth but it is weaker. The different level of visibility of the QW states along the two azimuthal directions is attributed to differences in the background shape. The $\operatorname{Ag}(111)$ Schockley surface state is clearly visible and more intense near normal emission. At the nominal coverage of 4 ML, the STM images shows predominance of $2 \mathrm{D}$ structure in the form of very wide (tens of nanometers) islands 7-8 ML high, in agreement with the measured binding energies of the QWSs (1.5 eV and 2.6 eV for QW1 and QW2 respectively) corresponding to a 7-8 ML Ag film. Data acquired along the $<100>$ and $<110>$ azimuth, which lies at $45^{\circ}$ relative to the stripes domains, show the same dispersion. We therefore conclude that the QW states are due to 2D confinement of electrons in the wide Ag islands that are predominant at $4 \mathrm{ML}$ thickness, and not on the Ag stripes that coexist with the islands at 4 ML but are predominant at lower Ag coverage. The same conclusion clearly applies to QW states observed at higher coverage.

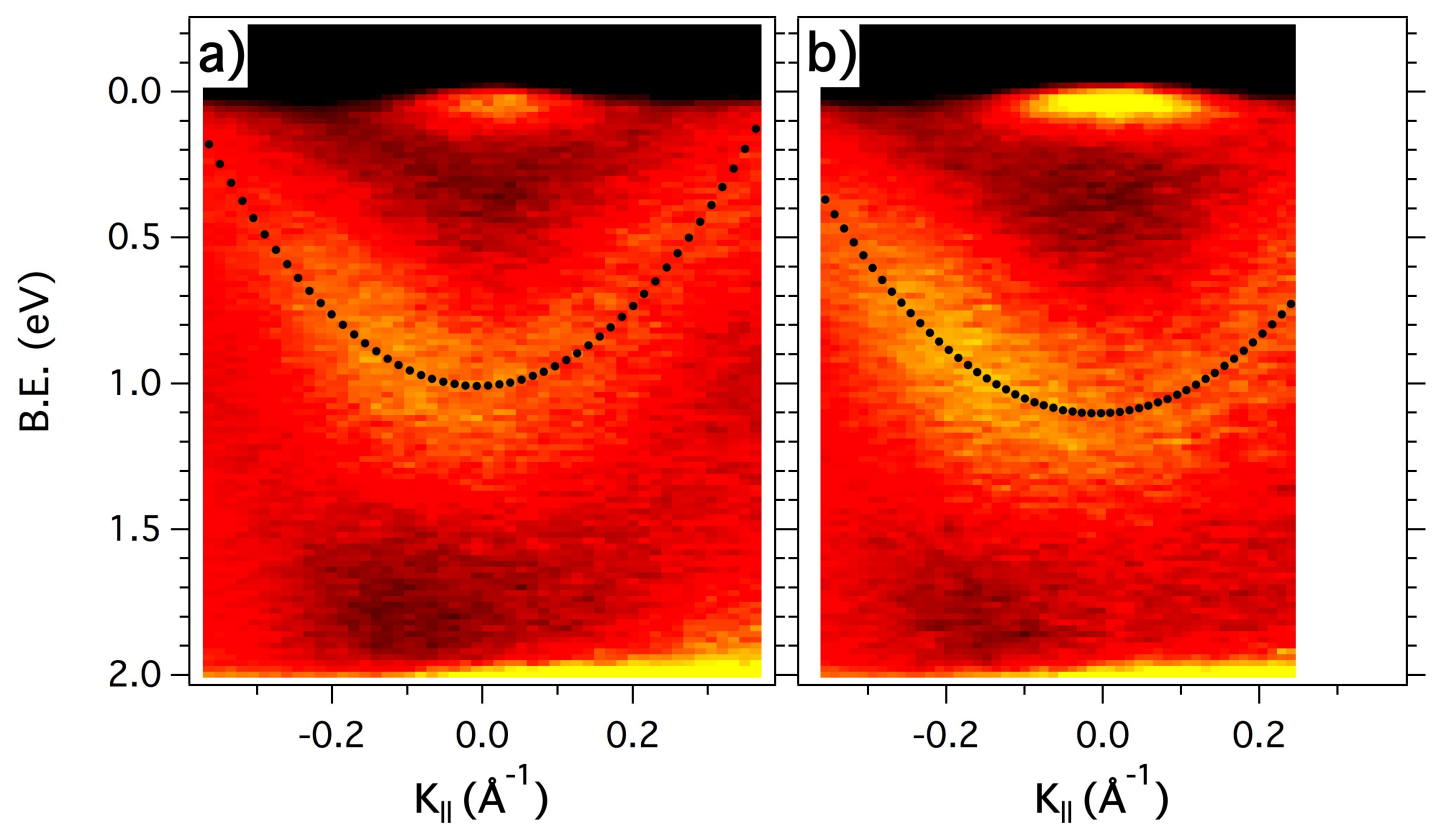


Figure 6. ARPES data acquired on $8 \mathrm{ML}$ of Ag deposited on 0.25 ML c(2x2)-N/Cu(001). Black dotted line: measured dispersion of the QW states. a) ARPES along the $<100>$ azimuth. b) ARPES along the $<110>$ azimuth. Photon energy hv=47.7 eV.

For an Ag coverage $<2 \mathrm{ML}$, where the stripe-shaped growth of Ag is predominant no QW state was observed despite the fact that the thickness of the Ag islands on a $\mathrm{Cu}(001)$ surface pre-covered with $0.25 \mathrm{ML}$ of $\mathrm{N}$ can reach the height of 4 layers. Note that with 4 layers height it is very likely that the bottom of the QW dispersion curve (which lies at a binding energy of approximately 2.9 $\mathrm{eV}$ ) is superimposed to the $\mathrm{Cu} 3 \mathrm{~d}$ structure and cannot be observed. For a given order $n$ in fact the binding energy of the QW decreases with the thickness [40, 49]. The lack of QW in the stripeshaped Ag overlayers can find several explanations, such as the average height of the islands is too small and irregular or the width of the islands is too irregular due to the faceting at the islands corners (from the STM images it can be noted that the Ag overlayer is very precisely confined by the $\mathrm{N}$ islands) and cause broadening of the QW states so that they are difficult to observe (see Fig.2). Superposition of the $\mathrm{Cu} 3 \mathrm{~d}$ band with the QW can be also another reason.

Fig.6 shows the QW states observed at a coverage of 8 ML (see Fig. 2e for the corresponding STM image) where the average thickness of the $\mathrm{Ag}$ islands is $10 \mathrm{ML}$, and also in this case there is agreement with the binding energies of the QWSs $(1 \mathrm{eV}$ and $2 \mathrm{eV}$ for QW1 and QW2 respectively, with QW2 state hardly visible) corresponding to a $10 \mathrm{ML}$ Ag film. The QW structure is still broad, which is again an indication of nonuniform thickness of the Ag layer. Also in this case the dispersion of the QW is the same along different azimuthal directions. ARPES data were also acquired for $\mathrm{Ag}$ deposition on clean $\mathrm{Cu}(001)$, where the dispersion of the QW states is identical to the one shown on the $\mathrm{N}$-modified surface. 


\section{Conclusions}

We have studied the growth of $\mathrm{Ag}$ on the subsaturated $c(2 \times 2)-\mathrm{N} / \mathrm{Cu}(001)$ surface with an $\mathrm{N}$ precoverage of $0.25 \mathrm{ML}$. This $\mathrm{N}$ modified $\mathrm{Cu}(001)$ surface consists of about $50 \%$ striped domains of clean $\mathrm{Cu}(001)$ where the stripes run along the $<100>$ azimuth and have a regular width. These clean $\mathrm{Cu}$ stripes are delimited by arrays of $\mathrm{c}(2 \times 2)-\mathrm{N}$ islands with a regular size that are separated by one line of atomic $\mathrm{Cu}$. Up to a coverage of $1 \mathrm{ML}$ in volume, the $\mathrm{Ag}$ overlayer growth is confined by the $\mathrm{N}$ islands onto the clean $\mathrm{Cu}$ islands. At a volume corresponding to $1 \mathrm{ML}$ of $\mathrm{Ag}$ the growth starts to spill-over the $\mathrm{N}$ covered part of the surface and formation of $2 \mathrm{D}$ structures begins to occur at step edges. However the preferential Ag-on-Ag growth continues and the thickness of the islands grows more quickly than it would be if it were determined by the volume of deposited Ag. The structure consisting of mostly separated islands continues in fact up to a coverage of $8 \mathrm{ML}$ where all the islands begin to coalesce to form a uniform film. The wide islands formed at coverages above $4 \mathrm{ML}$ in volume (7-8 ML thickness) gives rise to QW states emission observed in ARPES. These QW states have been assigned to 2D confinement of electrons in wide islands, each of them behaving like a film. The measured binding energy of the QW states is consistent with the height of the islands as measured with STM.

\section{Acknowledgements.}

Elettra infrastructure is acknowledged for providing access to synchrotron radiation. 


\section{References}

[1] S. L. Silva and F. M. Leibsle, Surf. Sci. 440, L835 (1999).

[2] R. Plass, J. A. Last, N. C. Bartelt and G. L. Kellogg, Nature 412, 875 (2001).

[3] S. Helveg, W. X. Li, N. C. Bartelt, S. Horch, E. Laegsgaard, B. Hammer and F. Besenbacher, Phys. Rev. Lett. 98, 115501(2007).

[4] M. Grundmann, Physica E 5, 167 (2000).

[5] H-Y Liu, B. Xu, Y-Q Wei, D. Ding, J.-J. Qian, Q. Han, J.-B. Liang and Z.-G. Wang, Appl. Phys. Lett. 79, 2868 (2001).

[6] H. Eisele, A. Lenz, R. Heitz, R. Timm, M. Dähne, Y. Temko, T. Suzuki and K. Jacobi, J. Appl. Phys. 104, 124301(2008).

[7] T. Ohta, A. Bostwick, T. Seyller, K. Horn and E. Rotenberg, Science 313, 951(2006).

[8] P. W. Sutter, J.-I. Flege and E. A. Sutter, Nature Mat. 7, 406 (2008).

[9] J. Campos-Delgado, J. M. Romo-Herrera, X. Jia, D.A. Cullen, H. Muramatsu, Y.A. Kim, T.Hayashi, Z. Ren, D.J. Smith, Y. Okuno, T. Ohba, H. Kanoh, K. Kaneko, M. Endo, H. Terrones, M.S. Dresselhaus, M. Terrones, Nanolett. 8, 2773 (2008).

[10] Z. Chen, W. Zhang, C.-A. Palma et al, J. Am. Chem. Soc. 138, 15488 (2016).

[11] S. D’Addato, V. Grillo, S. Altieri, S. Frabboni and S. Valeri, Appl. Surf. Sci. 260, 13 (2012).

[12] C. Carbone, S. Gardonio, P. Moras et al., Adv. Func. Mat. 21, 1212 (2011).

[13] F. M. Leibsle, C. F. J. Flipse and A. W. Robinson, Phys. Rev. B 47, 15865 (1993).

[14] F. M. Leibsle, S. S. Dhesi, S. D. Barrett and A. W. Robinson, Surf. Sci. 317, 309 (1994).

[15] C. Cohen, H. Ellmer, J. M. Guigner, A. L'Hoir, G. Prévot, D. Schmaus and M. Sotto, Surf. Sci. 490, 336 (2001).

[16] B. Croset, Y. Girard, G. Prévot, M. Sotto, Y. Garreau, R. Pinchaux , and M. Sauvage-Simkin, Phys, Rev. Lett. 88, 056103 (2002).

[17] M. Sotto, S. Gauthier, F. Pourmir, S. Rousset and J. Klein, Surf. Sci. 371, 658 (1997).

[18] M. Sotto and B. Croset, Surf. Sci. 461, 78 (2000).

[19] S. D'Addato, F. Borgatti, R. Felici and P. Finetti, Surf. Sci. 606, 813 (2012). 
[20] M. Yamada, N. Kawamura, K. Nakatsuji and F. Komori, e-J. Surf. Sci. Nanotech 14, 43

(2016).

[21] T. Hattori, M. Yamada and F. Komori, Surf. Sci. 655, 1 (2017).

[22] T. Parker, L. Wilson, N. Condon and F. Leibsle, Phys. Rev. B 56, 6458 (1997).

[23] Y. Matsumoto and K.-I. Tanaka, Jpn. J. Appl. Phys. 37, L154 (1998).

[24] K. Mukai, Y. Matsumoto, K. Tanaka and F. Komori, Surf. Sci. 450, 44 (2000).

[25] S. L. Silva, C. R. Jenkins, S. M. York and F. M. Leibsle, Appl. Phys. Lett. 76, 1128 (2000).

[26] G. Prévot, H Guesmi and B. Croset, Surf. Sci. 601, 2017 (2007).

[27] K. Nakatsuji, Y. Yoshimoto, D. Sekiba, S. Doi, T. Iimori, K. Yagyu, Y. Takagi, S.-Y. Ohno,

H. Miyaoka M. Yamada, F. Komori, K. Amemiya, D. Matsumura, T. Ohta, Phys. Rev. B 77, $235436(2008)$.

[28] S. D’Addato, C. Binns and P. Finetti, Surf. Sci. 442, 74 (1999).

[29] P. Finetti, F. Borgatti, R. Felici, R. Gunnella and S. D’Addato, Appl. Surf. Sci. 212, 85 (2003).

[30] S. D’Addato, R. Gunnella, F. Borgatti, R. Felici and P. Finetti, Surf. Sci. 601, 329 (2007).

[31] K.-D. Lee, T. Iimori and F. Komori, Surf. Sci. 454-456, 860 (2000).

[32] P. Finetti, V. R. Dhanak, C. Binns, L. W. Edmonds, S. H. Baker and S. D’Addato, J. Electron Spectrosc. Rel. Phenom. 114, 251 (2001).

[33] Y. Takagi, K. Isami, I. Yamamoto, T. Nakagawa and T. Yokoyama, Phys. Rev. B 81, 035422 (2010).

[34] S. M. York and F. M. Leibsle, Appl. Phys. Lett. 78, 2763 (2001).

[35] P. Sprunger, E. Laegsgaard and F. Besenbacher, Phys. Rev. B 54, 8163 (1996).

[36] J. G. Tobin, S. W. Robey and D. A. Shirley, Phys. Rev. B 33, 2270 (1986).

[37] J. G. Tobin, S. W. Robey, L. E. Klebanoff and D. A. Shirley, Phys. Rev. B 35, 9056 (1987).

[38] M.A. Mueller, A. Samsavar, T. Miller and T.-C. Chiang, Phys. Rev. B 40, 5845 (1989).

[39] M.A. Mueller, T. Miller and T.-C. Chiang, Phys. Rev. B 41, 5214 (1990).

[40] J.J. Paggel, T. Miller and T.-C. Chiang, Science 283, 170 (1999). 
[41] T.-C. Chiang, Surf. Sci. Rep. 39, 181 (2000).

[42] D.A. Evans, M. Alonso, R. Cimino and K. Horn, Phys. Rev. Lett. 70, 3483 (1993).

[43] P. Moras, D. Topwal et al., Phys. Rev. B 80, 205418 (2009).

[44] P. Moras, G. Bihlmayer, E. Vescovo, P. M. Sheverdyaeva, M. Papagno, L. Ferrari and C. Carbone, J. Phys.: Condensed Matter 29, 495806 (2017).

[45] P.W. Palmberg and T.N. Rhodin, J. Chem. Phys. 49, 134 (1968).

[46] J. Hayoz, D. Naumović, R. Fasel, P. Aebi and L.Schlapbach, Surf. Sci. 373, 153 (1997).

[47] H. Sheng and E. Ma, Phys. Rev. B 61, 9979 (2000).

[48] D. Sekiba, S. Doi, K. Nakatsuji and F. Komori, Surf. Sci. 590 (2005) 138.

[49] I. Matsuda, H.W Yeom, T. Tanikawa, K. Tono, T. Nagao, S. Hasegawa and T. Ohta, Phys. Rev. B 63, 125325 (2001). 